\title{
Editorial: Philosophical Fences
}

According to Jacques Monod, the Nobel prize-winning biologist, 'the universe was not pregnant with life, nor the biosphere with man'.

The work of the neurobiologist Benjamin Libet is often taken to show that free will is an illusion. When we 'freely' decide to do something, a good half-second before our conscious decision, there is unconscious cerebral initiation of the behaviour we mistakenly believe ourselves to be choosing later.

Joseph Conrad's novel, Lord Fim centres round the incident when, as a young man the seaman Jim jumps from his sinking ship into a lifeboat, leaving hundreds of passengers to their fate. All his life Jim ponders that decision. Did he choose to jump, or was hein a metaphysical sense-pushed?

In his recent book Straw Dogs John Gray takes the episode of Jim and the lifeboat and the Libet data to show that we are not really free, and more radically that human agency and selfhood are illusions. Like many others, he is also more than content with the deflationary implications of Monod's conclusion: life itself is a fluke, and we ourselves no more than a lucky throw in the cosmic lottery. And humanity itself, in its despoliation of the planet, is a plague animal. Along with James Lovelock, Gray concludes that 'Gaia is suffering from a plague of people'.

Maybe so, and Gray's position is certainly one for which reasons can be given. But do the facts compel us to hold it? How could one fraught and problematic incident in a novel show us that there was no such thing as human freedom? At the very most it shows that in moments of panic and crisis we know not what to do.

Nor are the Libet data inconclusive. For one thing the experimental set-up is such that the subject has already decided to act in the way prescribed, having agreed to the experimenter's request to execute a particular finger-movement in a tightly controlled situation; only the moment of action is uncertain. Nor, as John Searle has pointed out, is it clear that the finger movement follows directly on the unconscious readiness potential. There is a temporal gap between that and the conscious intention, and also another gap between that and the action. In any case Libet's subjects could at any time demonstrate a higher-level freedom by simply withdrawing from the experiment. 


\section{Editorial}

And if Monod interprets biology in one way, another Nobel prize winning biologist from France offers us a completely opposite interpretation. In his book Vital Dust Christian de Duve provides a detailed and elegant demonstration of the way elements of randomness both prior to the emergence of life and subsequently are going to be so constrained by the environment and by the possibilities internal to matter, organic and inorganic, as to make both life itself and intelligent life like ours highly likely.

So are we rational vital dust or an irrational self-deluding plague?

D. H. Lawrence wrote of the novel that it incapable of the absolute'; it is 'quick' and in it there is always 'a tom-cat, a black tom-cat that pounces on the white dove of the Word... A theosophist, or a Christian or a Holy Roller may be contained in a novelist. But a novelist may not put up a fence'. No more, it seems, should a philosopher. 